Chapman University

Chapman University Digital Commons

Pharmacy Faculty Articles and Research

School of Pharmacy

1999

\title{
Reversible Nonthrombocytopenic Palpable Purpura Associated with Metoclopramide
}

Jeffery A. Goad

Chapman University,goad@chapman.edu

Follow this and additional works at: http://digitalcommons.chapman.edu/pharmacy_articles

Part of the Pharmaceutical Preparations Commons, Pharmacy and Pharmaceutical Sciences $\underline{\text { Commons, }}$ and the Skin and Connective Tissue Diseases Commons

\section{Recommended Citation}

Goad JA. Reversible Nonthrombocytopenic Palpable Purpura Associated with Metoclopramide. Ann of Pharmacother 1999;33:35-7 DOI:10.1345/aph.18058

This Article is brought to you for free and open access by the School of Pharmacy at Chapman University Digital Commons. It has been accepted for inclusion in Pharmacy Faculty Articles and Research by an authorized administrator of Chapman University Digital Commons. For more information, please contact laughtin@chapman.edu. 


\section{Reversible Nonthrombocytopenic Palpable Purpura Associated with Metoclopramide}

\section{Comments}

This is a pre-copy-editing, author-produced PDF of an article accepted for publication at Annals of Pharmacotherapy, volume 33, in 1999 following peer review. The definitive publisher-authenticated version is available online at DOI: 10.1345/aph.18058

\section{Copyright}

Sage 


\title{
REVERSABLE NON-THROMBOCYTOPENIC PALPABLE PURPURA ASSOCIATED WITH METOCLOPRAMIDE
}

\author{
Jeffery A. Goad, Pharm.D., BCPS \\ Assistant Professor of Clinical Pharmacy \\ Department of Clinical Pharmacy \\ University of the Southern California, School of Pharmacy \\ Correspondence and Reprints: \\ Jeffery A. Goad, Pharm.D., BCPS \\ USC School of Pharmacy \\ 1985 Zonal Avenue \\ Los Angeles, CA 90033 \\ 323-442-1907 (office) \\ 323-442-1395 (fax) \\ goad@hsc.usc.edu (email)
}

Acknowledgment: The author would like to acknowledge the help of Dr. Tina Eng who was a pharmacy student at the time. 
Objective: To report a case of reversible non-thrombocytopenic palpable purpura associated with metoclopramide

Case Summary: A 72 year old man was admitted for worsening palpable purpura over a 2 day period. Two days prior to admission, metoclopramide, $10 \mathrm{mg}$ orally three times daily, was started for a gastrointestinal condition. Upon admission, all drugs were continued except metoclopramide. Over the next 2 days, purpura began to resolve. Platelet count was within normal limits upon admission and the patient suffered no serious consequences because of the purpura.

Discussion: According to the available literature, reversible nonthrombocytopenic palpable purpura has not been previously reported with metoclopramide. A search of Medline (1966 to 1998) and International Pharmaceutical Abstracts (1970 to 1998) did not reveal a similar case. Although a rechallenge of metoclopramide was not tried, this case appears to demonstrate a temporal relationship between the initiation and discontinuation of metoclopramide and the onset and resolution of symptoms. Similar cases in the literature of this reaction have been reported with procainamide, which is structurally similar to metoclopramide.

Conclusion: Metoclopramide may cause reversible non-thrombocytopenic vascular-type palpable purpura. Discontinuation of the drug appeared to be responsible for the resolution of symptoms. 
Metoclopramide has a variety of indications including gastrointestinal motility disorders, chemotherapy-induced vomiting, gastroesophageal reflux, and diabetic gastroparesis. Classified as a benzamide, it is structurally similar to procainamide, but lacks any significant local anesthetic or antiarrhythmic actions. Its effects on the central nervous system and gastrointestinal system are apparently mediated by dopaminergic blockade. Rash and methemoglobinemia are rarely reported compared to the more common adverse effects such as restlessness, drowsiness, diarrhea, and extrapyramidal reactions. $^{1}$

Although the manufacturer of metoclopramide ${ }^{1}$ has reported maculopapular rashes, purpuric eruptions such as those displayed by this patient have not been reported. This is a report of a patient who apparently experienced reversible non-thrombocytopenic palpable purpura related to the oral administration of metoclopramide.

Case Report: A 72 year old man presented to the emergency department complaining of "patching" on his legs which had progressively worsened over the past 2 days. He did not complain of pruritus or pain from the skin eruption. Vital signs and temperature were within normal limits. Physical examination revealed an extensive non-contiguous red patchy palpable skin eruption covering approximately $80 \%$ of the patient's lower extremities. The skin eruptions did not blanche upon depression, thus purpura was suspected 
rather than a local vasodilatory reaction. The patient had mild pedal edema, presumed secondary to congestive heart failure, consistent with an exam performed 2 days previously.

The patient was started on metoclopramide orally $10 \mathrm{mg}$ three times daily 2 days prior to admission for relief of abdominal pain, presumably secondary to diabetic gastroparesis. Other outpatient medications included dioxin $0.125 \mathrm{mg} / \mathrm{day}$, albuterol 2 puffs every 4 hours, amlodipine $5 \mathrm{mg} / \mathrm{day}$, aspirin $325 \mathrm{mg} /$ day, beclomethasone 2 puffs every 4 hours, furosemide $80 \mathrm{mg}$ two times daily, ipratropium bromide 2 puffs every 4 hours, insulin (70/30) 80 units every morning and 40 units every evening, and gemfibrozil $600 \mathrm{mg}$ twice daily. The patient reported no known drug allergies. Except for metoclopramide, all other medications had been taken chronically for the last year without significant changes.

The patient's past medical history was significant for congestive heart failure, type 1 diabetes, hypertension, chronic obstructive pulmonary disease (requiring home oxygen), and gastroparesis apparently secondary to diabetes. The patient had a 150 pack year history of smoking, but quit 2 years ago. In addition, he drank 12 beers per day for 20 years, but states he quit 2 years ago as well. Labs on admission were as follows: $\mathrm{WBC}=8.8 \times 10^{3}$ cumm $(4-10 \mathrm{x}$ $\left.10^{3} \mathrm{cumm}\right)$, platelets $=368 \times 10^{3} / \mathrm{cumm}\left(150-450 \times 10^{3} \mathrm{cumm}\right)$, hemoglobin $=$ $11.2 \mathrm{~g} / \mathrm{dL}(14-18 \mathrm{~g} / \mathrm{dL})$, hematocrit $=33.2 \%(36-54 \%)$, glucose $=197 \mathrm{mg} / \mathrm{dL}$ $(60-110 \mathrm{mg} / \mathrm{dL})$, and serum creatinine $=2.9 \mathrm{mg} / \mathrm{dL}(0.7-1.4 \mathrm{mg} / \mathrm{dL})$. All other routine labs were within normal limits. 
Metoclopramide was discontinued on admission to the hospital and all other outpatient medications were continued. Over the next 2 days, there was a significant reduction in the extent of purpura over the patient's extremities. No specific therapy was required to aid in the resolution of the reaction. A platelet count was not obtained prior to discharge since the admission lab value was within normal limits. The patient displayed no signs and symptoms of bleeding and since the initial platelet count was within normal limits, no other tests for coagulation were ordered. Purpura began to resolve shortly after admission, thus dermatology was not consulted and a skin biopsy was not obtained. The patient was not rechallenged with metoclopramide and since he did not complain of abdominal pain, no other treatment was initiated. No other complications were experienced during the patient's 3 days of hospitalization.

\section{Discussion}

Metoclopramide was first introduced in the 1960s as an antiemetic.

Since then, many adverse effects have been reported to the manufacturer and documented in the literature. When Pinder et al reviewed the literature on the use and pharmacologic properties of metoclopramide in 1976, the only dermatologic effect noted was an urticarial or maculopapular rash. ${ }^{2}$ In 1982, a case of thrombocytopenic purpura related to metoclopramide was reported as a letter to the editor in the Spanish literature. ${ }^{3}$ A reaction associated with metoclopramide similar to that experienced by our patient in this case report 
was not found in either Medline (1966 to 1998) or International

Pharmaceutical Abstracts (1970 to 1998). Although causality is difficult to prove, it is reasonable to postulate that the purpura experienced by this patient was associated with metoclopramide. The timing of the purpura coincided with the initiation of metoclopramide and resolution occurred shortly after its discontinuation. All other medications had been used chronically for the past year by the patient and were continued upon admission to this Veterans Hospital. A similar literature search did not reveal an apparent relationship between the patient's reversible non-thrombocytopenic palpable purpuric reaction and any of the other medications he was taking.

Purpura is characterized by extravasation of red blood cells into the dermis, thus, unlike erythema and telangiectasias, it does not blanche with pressure. Purpura can be divided into three main categories. ${ }^{4}$ The first category is intravascular and is usually accompanied by nonpalpable purpura. Aspirin and methyldopa have been associated with this type of purpura. The second category is known as extravascular or miscellaneous and may be palpable or nonpalpable. Possible etiologies of this category include toxins, venoms, scurvy, and corticosteroids (usually reported as nonpalpable). ${ }^{5}$ Although the patient in this case report was using inhaled beclomethasone, a topical corticosteroid, it is unlikely that this was the cause of his purpura as he had been using it for over a year; reactions with corticosteroids usually present as nonpalpable purpura; and systemic absorption is minimal. The third category is termed vascular and is usually characterized by palpable purpura. 
In fact, one of the most likely causes of palpable purpura is inflammatory small-vessel vaculitis. ${ }^{6}$ This type of purely cutaneous vasculitis is often associated with drugs such as penicillin, sulfonamides, and phenytoin. ${ }^{4}$ Symptoms may include pruritus, burning and, less often, pain, but the presence or absence of these symptoms is not considered integral to the diagnosis. $^{4}$

This patient most likely had an inflammatory vascular cutaneous reaction. The lack of thrombocytopenia, temporal association with a drug, and palpable nature of the purpura further supports this description.

Procainamide, an antiarrhythmic agent, is classified as an alkaloid with a substituted amide linkage. This structure is consistent with the benzamides, notably metoclopramide. Structural similarities between different classes of drugs may help explain similarities in adverse effect profiles. For instance, procainamide was associated with a purpuric ecchymotic eruption in a 74 year old male. ${ }^{7}$ This patient had a normal platelet count, but the thromboplastin time was noted to be elevated. In a case series by Knox et al., urticarial vasculitis was associated with procainamide therapy in a 70 year old male and a 74 year old male. ${ }^{8}$ In the latter case, the rash began to resolve on day 3 after discontinuing procainamide and in the former case, resolution occurred 4 days after discontinuation. The mechanism of this procainamide adverse reaction is not well understood. One might speculate that since metoclopramide and procainamide are structurally similar, the reaction noted in our patient might be expected based on similar reactions reported from procainamide. 
This case report illustrates a previously unreported case of reversible non-thrombocytopenic vascular-type palpable purpura. Clinicians may want to be aware of structural similarities between drugs and drug classes when evaluating previously undocumented reactions to identify and manage them appropriately. 


\section{References}

1. Invamed, Inc. Metoclopramide package insert. Dayton, NJ; 1994

2. Pinder RM, Brogden RN, Sawyer PR, et.al. Metoclopramide: a review of its pharmacological properties and clinical use. Drugs 1976;12:81131

3. Nomdedeu B, Ribera-Santasusana J M, Sanchez-Bisono J, Montserrat E, Rozman C. Megakaryocytic thrombocytopenic purpura caused by metoclopramide. Sangre [letter] 1982;21(1):97-8

4. Stevens GL, Adelman HM, Wallach PM. Palpable purpura: An algorithmic approach. Am Family Physician. 1995;52(5):1355-62

5. Schreiner DT. Purpura. Dermatol. Clin. 1989;7(3):481-90

6. Lightfoot RW. Palpable purpura: identifying the cause. Hosp Pract [Off Ed]. 1992;27:39-47

7. Dolan DL. Angiitis following procainamide therapy. Missouri Medicine. 1968;65(5):365-6

8. Knox JP, Welykyj SE, Gradini R, et. al. Procainamide-induced urticarial vasculitis. Cutis 1988;42:469-472 